\title{
Genotypic Variation in Constitutive and Induced Resistance in Grapes Against Spider Mite (Acari: Tetranychidae) Herbivores
}

\author{
GREGORY ENGLISH-LOEB, ${ }^{1}$ RICHARD KARBAN, AND M. ANDREW WALKER ${ }^{2}$ \\ Department of Entomology, University of California, Davis, CA 95616
}

\begin{abstract}
Environ. Entomol. 27(2): 297-304 (1998)
ABSTRACT We examined genotypic variation in constitutive and induced resistance in grapes against Willamette spider mites, Eotetranychus willametti Ewing, and Pacific spider mites, Tetranychus pacificus McGregor, 2 common species of tetranychid mites found in California vineyards. We found evidence that early-season injury by Pacific mites induced resistance against subsequent Willamette mite populations but early-season injury by Willamette mites did not induce resistance against subsequent Willamette mite populations. Significant levels of induction were detected for several cultivars of the Old World species Vitis vinifera $\mathrm{L}$. as well as the North American species $V$ californica Bentham. Phylogenetic relationships among grape genotypes explained little of the variation we observed in induced resistance. Phylogenetic relatedness among grapes did help explain patterns of constitutive resistance for Pacific mites; cultivars of V. vinifera $L$. tended to be susceptible, whereas North American species were resistant. Willamette mites, however, performed well on some Old World cultivars and 2 North American species of Vitis that are native to California. We did not find any strong evidence of a negative correlation between constitutive resistance and strength of induction for these grape genotypes. Our results show that several factors contribute to variation in constitutive and induced resistance in grapes against these 2 species of spider mites, including grape genotype, previous history of mite injury (induction), the species of mite causing previous injury, and to some extent, phylogenetic relatedness among grapes. We also suspect that mite genotype has important influences.
\end{abstract}

KEY WORDS Vitaceae, spider mite, induced resistance, constitutive resistance, phylogeny

WHEN PLANTS ARE fed on by herbivores or injured in other ways they often change physiologically, biochemically, and even morphologically. These changes sometimes influence current or subsequent herbivores. The fact that previous damage can make plants less suitable to subsequent herbivores has potentially important implications for the population ecology and evolution of both the plants and their herbivores (Karban and Myers 1989). Induced responses and induced resistance have been well documented and have been found in many different plant taxa (Karban and Baldwin 1997). In some of these cases, it appears that plants benefit from induced responses by reducing subsequent herbivore loads (termed induced defenses), although it is often difficult to show these benefits experimentally (Karban and Baldwin 1997). Nevertheless, agriculturists have been very interested in examining the conditions under which induced resistance is advantageous in managing pests. For example, plant pathologists have developed commercial techniques in which they inoculate plants with less virulent pathogens to induce defenses against more virulent pathogens (Campbell and MacDonald 1989, White and Antoniw 1989). The use of induced resistance against

\footnotetext{
${ }^{1}$ Department of Entomology, Cornell University, New York State Agricultural Experiment Station, Geneva, NY 14456.

2 Department of Viticulture and Enology, University of California, Davis, CA 95616.
}

arthropod pests, however, has been much less well developed (Karban and Baldwin 1997).

Despite a large catalog of plant species for which induced resistance has been documented, we have little information about existing genetic variation of this trait among and within closely related species (Anderson et al. 1989, Zangerl and Berenbaum 1990, Thaler and Karban 1997). This information is important for both basic and applied reasons. By comparing the presence or absence of induced resistance among species with known phylogenies we can gain insights into its evolution (Miles and Dunham 1993). Applied workers may be able to take advantage of induced resistance in traditional breeding programs or through genetic engineering to enhance crop protection.

Induced resistance is frequently viewed as an alternative tactic to constitutive resistance for dealing with parasites and herbivores based on the energetic argument that plants, under some environmental situations, can reduce defense costs by producing them only when needed (Mattson et al. 1988, Herms and Mattson 1992). It is not clear, however, whether there is necessarily a trade-off between induced verses constitutive defense in plants (Zangerl and Berenbaum 1990, Brody and Karban 1992, Hildmann et al. 1992), although this question has not been examined for many systems. An understanding of the relationship between constitutive and induced resistance will be 
important in defining how best to use induced resistance in agriculture.

Over the past $10 \mathrm{yr}$ we have been exploring the interactions between spider mites and grape plants (English-Loeb and Karban 1988; Karban and EnglishLoeb 1990; English-Loeb et al. 1993; Karban et al. 1994, 1997; Hougen-Eitzman and Karban 1995). We have found strong evidence that early-season feeding damage by Willamette mites, Eotetranychus willametti Ewing (the less serious pest in the areas where we worked) increased grape plant resistance later in the season against the Pacific mite, Tetranychus pacificus McGregor (the more serious pest). Several mechanisms appear to be involved in this interaction, but induced resistance is an important component (Hougen-Eitzman and Karban 1995).

Willamette mites have a more restricted host range than Pacific mites, reported from cultivated and native grapes (Vitis sp), box elder, Acer negundo, 2 western oak species, Quercus lobata and Q. gariana, and Pursha tridentata (Pritchard and Baker 1952, Jeppson et al. 1975). Pacific mites, however, have a much broader host range including a number of important agricultural crops such as grapes, almonds, citrus, plum, apricot, cherry, walnuts, beans, melons, blackberry, alfalfa, clover, and cotton (McGregor 1950, Pritchard and Baker 1952, Jeppson et al. 1975). In addition, Pacific mites have been collected from a number of different native hosts including Ceanothus sp., Salvia sp., Stachys sp., Helianthus sp., Ipomoea sp., Ribes sp., Rubus sp., Chenopodium sp., and Vicia sp. (McGregor 1950, Pritchard and Baker 1952). Both species are distributed primarily in the western United States (Pritchard and Baker 1952).

Our past research has found that early-season feeding damage by Willamette mites negatively affects population sizes of Pacific mites using a single grape cultivar ('Zinfandel'). We have less information about resistance (induced or constitutive) in other grape cultivars or grape species. Similarly, we had no information about how early-season damage by Pacific mites affects subsequent Willamette mite populations. Based on theoretical arguments, Rhoades (1985) proposed that generalist feeders such as Pacific mites are more likely to induce resistance in host plants than specialist feeders like Willamette mites. Few experiments have been conducted to test this hypothesis explicitly (but see Bowers and Stamp 1993).

In this current investigation we examined patterns of induced and constitutive resistance in a plant/herbivore system where phylogenetic relationships among the different plant species are well known and we have clear evidence that induced resistance plays a role in the interaction. We addressed the following 4 objectives: (1) Compare constitutive and induced resistance in grapes, Vitis (several species and cultivars) against the Willamette and Pacific spider mites. (2) Assess whether grape phylogeny helps explain patterns of constitutive and induced resistance. (3) Assess whether there is evidence of a trade-off between constitutive and induced resistance in grapes. (4) Test the prediction that a polyphagous spider mite causes a larger induced response in grapes than a second, more specialized spider mite species.

\section{Materials and Methods}

Grape Varieties and Species. In this common garden experiment we established cuttings from 6 different $V$. vinifera cultivars originating from the Old World and 3 other species of Vitis originating from North America. V. vinifera is native to Eurasia and is the progenitor of most wine and table grapes grown commercially around the world. The 6 cultivars of $V$. vinifera used were 'Thompson Seedless', 'Flame Seedless', 'Zinfandel', 'Carignane', 'Cabernet Sauvignon', and 'Chardonnay'. Cane cuttings of these 6 cultivars were obtained from plantings on the University of California at Davis campus and managed by the Department of Viticulture. The 3 other species of Vitis used in this experiment were V. californica Benth. (originating from two distinct sites in California), V. girdiana Munson (originating from Redlands, CA), and V, acerifolia Raf. (originating from a single site in Texas). One of the $V$. californica populations is located near Gold Hill, $\mathrm{OR} \approx$ $50 \mathrm{~km}$ north of the California border on Interstate 5 along the Rogue River, and the other population is located $\approx 50 \mathrm{~km}$ south and west of Sacramento along the Consumnes River in the northern San Joaquin valley near Lodi, CA. With the exception of the Consumnes River population, cane cuttings of these species were obtained from transplanted vines maintained at the National Clonal Germplasm Repository (operated by USDA) located in Winters, CA. Cane cuttings from grapes growing in the Consumnes River Preserve (operated by the Nature Conservancy) were collected in November 1992. All cane cuttings were kept in cold storage from November 1992 to February 1993.

We chose cultivars and species of grapes such that several major classes were represented in our experiment. This approach allowed us to examine whether patterns of constitutive and induced resistance are clustered along phylogenetic lines. Current taxonomy of grapes is based primarily on leaf morphology and to some extent on geographic distributions (Moore 1991). V. vinifera originated in the Middle East before widespread propagation throughout the world. Negrul (1938) first proposed 3 groupings of $V$. vinifera. His orientalis group was composed of the large oval-berried table grapes; the small-berried wine grapes of western Europe were grouped into occidentalis; and the intermediate types of eastern Europe were grouped into pontica. Thompson Seedless originated in the Middle East. Flame Seedless is a recent hybrid from Middle Eastern parents, 3/8ths of which were Thompson Seedless. Both of these cultivars are used as table grapes and represent the orientalis group in this experiment. Chardonnay and Cabernet Sauvignon are considered to have originated in Western Europe and are both small-berried wine grapes within occidentalis. Zinfandel and Carignane have intermediatesized berries and other features and fall into the pontica group. Hence, we used 2 representative $V$, vinifera 
cultivars from each of 3 groupings and geographic origins.

We chose native species of grapes indigenous to the western United States. V. californica and V. girdiana are both species from California and are classified into the same subgeneric grouping. These 2 species are related more distantly to $V$. acerifolia ( $V$. longii) from Texas and Oklahoma which was chosen as an outgroup and falls into a separate grouping of the North American Vitis species (Bailey 1934). In addition, V. acerifolia is a novel host plant for California populations of Willamette mites and Pacific mites, whereas $V$. californica and to some extent V. girdiana are not.

Propagation and Rearing of Vines. In February of 1993 we moved cane cuttings out of cold storage. Canes were first dipped in rooting compound $(4,000$ ppm IBA/NAA mix for $5 \mathrm{~s}$ ) and planted into a propagation bed filled with vermiculite and perlite (equal parts) and located in a greenhouse. The tops of the canes were covered with black plastic to maintain high humidity around the unopened buds and exposed bark. Canes were kept under these conditions for 1.5 mo at which time most canes had initiated both roots and shoots. We transplanted the rooted canes into the field on 19 and 20 April 1993. Our experimental plot was located near the University of California at Davis campus and managed by the Department of Viticulture and Enology. Vines were managed in accordance with normal viticultural practices with the exception that we never treated them with any pesticides except as noted under experimental procedures below. During the winter of 1993, all vines were spur-pruned, leaving 5-15 buds for the next season's growth.

Experimental Design. Rooted canes of the various cultivars and species of grapes were planted in a completely randomized block design. Because the soil was known to become increasingly sandy moving north to south, we blocked the vineyard. Within each block, vines were assigned to the following 3 treatments: (1) control (no early-season mites), (2) Willamette mites released early in the season, and (3) Pacific mites released early in the season. Our original plan was to plant 48 canes of each grape genotype ( 16 vines per treatment). Some genotypes, however, did not survive transplanting and never became established. All vines that survived transplanting grew well during 1993 and appeared healthy in the spring of 1994 when treatments were initiated. Total samples sizes were Thompson Seedless, 34; Flame Seedless, 36; Zinfandel, 48; Carignane, 46; Cabernet Sauvignon, 48; Chardonnay, $34 ; V$. californica (gold hill population), $30 ; \mathrm{V}$. californica (Consumnes River population), 30; V. girdiana, 32; $V$. Acerifolia, 29 . Sample sizes were roughly the same for the 3 treatments.

Vines assigned to receive early-season damage were inoculated with Willamette mites (treatment 2) or Pacific mites (treatment 3) on 11 and 14 April 1994, respectively. At this time, vines in our common garden plot had young shoots no longer than 5 or $10 \mathrm{~cm}$. Because Willamette mites are difficult to rear in the laboratory we acquired them from the field for this experiment. Leaves containing Willamette mites were collected from a Zinfandel vineyard just north of Bakersfield, CA, placed in a paper bag with wet toweling and stored in an ice chest for transportation north. The following day the leaves were attached to designated vines with a twistie. Based on a visual count of leaves before release, we infested each vine with $\approx 10$ adult females plus mites in other stages. We used a laboratory colony as our source of Pacific mites for this experiment. The colony was established in the summer of 1993 (originally collected from Zinfandel grapes growing near Lodi, CA) and reared in the laboratory on cotton cotyledons. For designated vines, we attached 4 cotyledons per vine, which contained $\approx 20$ adult female mites plus other mite stages.

After allowing the mites to feed and reproduce for $\approx 4$ wk (1.5-2 generations), we challenged each vine with both Willamette mites and Pacific mites. For each vine, we selected 2 similar sized shoots for releasing challenge mites. A survey of vines in the vineyard showed that mites released earlier in the season had not reached the terminal leaves of actively growing shoots. Hence, our bioassay mites were not augmented by the original release of mites. This assumption was confirmed later in the season. When we counted the challenge leaves we found very few Willamette mites from the early release infesting the Pacific mite challenge leaves $(0.04 \pm 0.03$ mites per leaf, mean $\pm \mathrm{SE}$ ) or Pacific mites infesting Willamette mite challenge leaves $(0.17 \pm 0.07)$. On 16 May we released Willamette mites on the terminal of one of these shoots at a rate of 133 mites (all stages) \pm 35 per shoot. A Zinfandel vineyard located near Fairfield, $\mathrm{CA}$, served as the source population. On 9 June the release leaf and leaf above it were brought back to the laboratory where the number of spider mites and spider mite predators (mainly predaceous phytoseiid mites and six-spotted thrips, Scolothrips sexmaculatus (Pergande), were determined using a dissecting scope.

Establishing the Pacific mite challenge proved more difficult. Initially, we attempted to release 50 eggs per terminal shoot on all vines on 18 May. Eggs from our laboratory colony were collected on filter paper using a Buchner funnel. The filter paper was then cut into sections, each containing approximately 50 viable eggs. However, a summer rain the next day washed eggs off the filter paper pieces off the shoot. Two days later (20 May) we released Pacific mites using cotyledons from our laboratory colony at a rate of 20 adults per shoot. These mites became established, but, unfortunately, when we brought leaves in for counting (20 June) we discovered that predators had built up by this time and virtually wiped out the populations. On 22 June we treated the shoots designated to receive Pacific mites with permethrin at a rate of $0.05 \mathrm{ml} /$ liter or $50 \mathrm{ppm}$. Permethrin kills insect and mite predators of spider mites but does not affect spider mites at the concentration used (unpublished data). On 24 June we released Pacific mites a 3rd time on designated shoots using mites from our laboratory colony and at a rate of approximately 20 adults per shoot. The permethrin effectively removed predators and this re- 
Table 1. ANOVA results assessing effect of vine cultivar or species (10 types) and type of early-season damage (induction with Willanette nites, Pacific mites, or nothing) on Willamette mite popolations later in the season

\begin{tabular}{lrcrr}
\hline \multicolumn{1}{c}{ Source } & df & Mean square & \multicolumn{1}{c}{$F$} & $P$ \\
\hline Early damige & 2 & 5.3758 & 15.45 & 0.0001 \\
Vine type & 9 & 7.8367 & 22.53 & 0.0001 \\
Block & 1 & 0.0142 & 0.04 & 0.8400 \\
Damage*Vine & 18 & 0.3694 & 1.06 & 0.3933 \\
Error & 335 & 0.3489 & & \\
\hline
\end{tabular}

lease was successful. On 11 July we collected the release leaf and the leaf above it and brought them back to the laboratory for counting. Although Pacific mite populations developed on these shoots, we were not able to assess whether the time delay or the pesticide interfered with our original treatments.

Statistics. We used analysis of variance (ANOVA, SAS Institute 1990) to assess the effect of vine type (species or cultivar), early damage (control, Willamette mite damage, Pacific mite damage), and block on subsequent densities of Willamette mites and $\mathrm{Pa}$ cific mites. We log transformed data to reduce problems of unequal variances. Population densities on control vines (no early-season releases) were used to assess level of constitutive resistance against Willamette or Pacific mites. Proportional differences between densities on vines receiving early-season Willamette or Pacific mite damage and control vines were used to assess induction.

To assess whether phylogenetic relationships help to explain patterns of constitutive or induced resistance, we compared results for $V$. vinifera varieties from the 3 regions of origin and North American species. Because of the lack of independence between species in phylogenetic analyses (Felsentein 1985), however, and the relatively few species and varieties used in our study, we are limited in the statistical inferences that we can draw.

\section{Results}

We found significant variation in the population size of Willamette mites as a function of grape variety or species $(P<0.0001$, Table 1$)$. In addition, mite damage early in the season affected numbers of Willamette mites later in the season, indicating an induced response $(P<0.0001$, Table 1$)$. The type of early damage did make a difference, however. Early damage by Pacific mites induced later resistance against Willamette mites (contrast $F=27.88$; $\mathrm{df}=1,33 ; P<$ 0.0001 , Fig. 1). Early damage by Willamette mites did not induce resistance against Willamette mites (contrast $F=1.55 ; \mathrm{df}=1,333 ; P=0.21$, Fig. 1). We did not detect a significant effect of block $(P=0.8)$ nor an interaction between grape genotype and type of early season damage $(P=0.44)$. The effect of early-season damage was not mediated through a build up of predators. Predaceous mite densities did vary among vine types $(F=4.92$; $\mathrm{df}=9,335 ; P<0.0001)$, but densities of predators were not influenced by whether vines

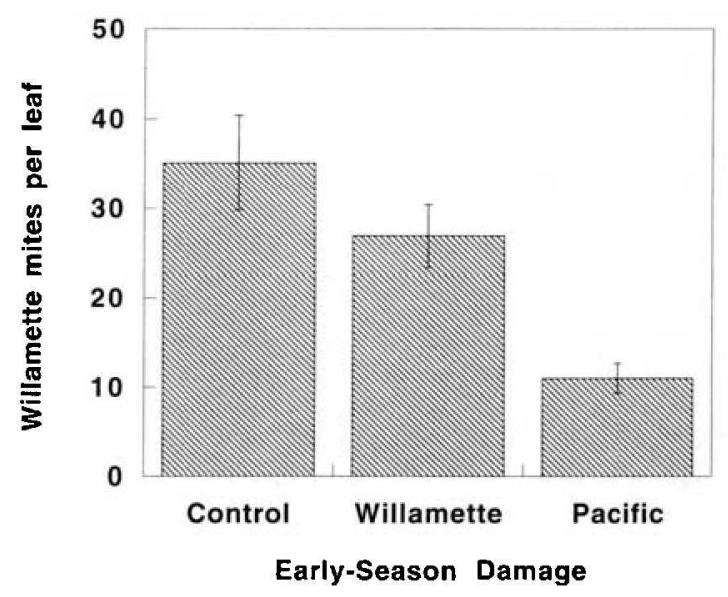

Fig. 1. Mean number of Willamette mites per leaf $( \pm 1$ $\mathrm{SE}$ ) on vines that did not receive early-season damage (control), vines that were damaged early in the season by Willamette mites, and vines that were damaged early in the season by Pacific mites. Means are averaged across vine cultivars and species.

received early-season Willamette mite or Pacific mite damage $(F=1.74 ; \mathrm{df}=2,335 ; P>0.15$ ). The mean number of predaceous mites found on Willamette challenge leaves from induced vines was only half the number found on leaves from control vines, indicating no buildup of predators (mean predaceous mites per Willamette challenge leaf for control vines $=1.0, \mathrm{SE}$ $=0.25$, mean for vines induced by Pacific mites $=0.5$, $\mathrm{SE}=0.09$ ).

With respect to variation in constitutive resistance against Willamette mites among varieties of $V$. vinif$e r a$, we found that the table grapes (Thompson Seedless and Flame Seedless) had high levels of constitutive resistance (low mite populations), whereas the wine variety Zinfandel was very susceptible. Other wine varieties were also much better hosts for Willamette mites than the 2 table grape varieties (Fig. 2). The North American species V. califormica was also a moderately good host for Willamette mites, supporting population sizes only slightly lower than on wine grapes (Fig. 2). The other two species of North American grapes, especially $V$. acerifolia from Texas, however, displayed greater levels of constitutive resistance. Taken together, these results suggest that constitutive resistance is a variable trait and occurs both in the Old World V. vinifera group (Thompson Seedless and Flame Seedless) and some North American species.

Induced resistance against Willamette mites (from early-season Pacific mite injury) was a variable trait across grape species and varieties and it did not appear to be restricted to certain grape lineages. For example, early-season damage by Pacific mites caused large reductions in Willamette mite populations for $V$. vinifera wine grapes relative to Willamette mite populations on control vines (especially Zinfandel, Carignane and Chardonnay) and in the North American species V. californica (Fig. 2). It is difficult to assess the 


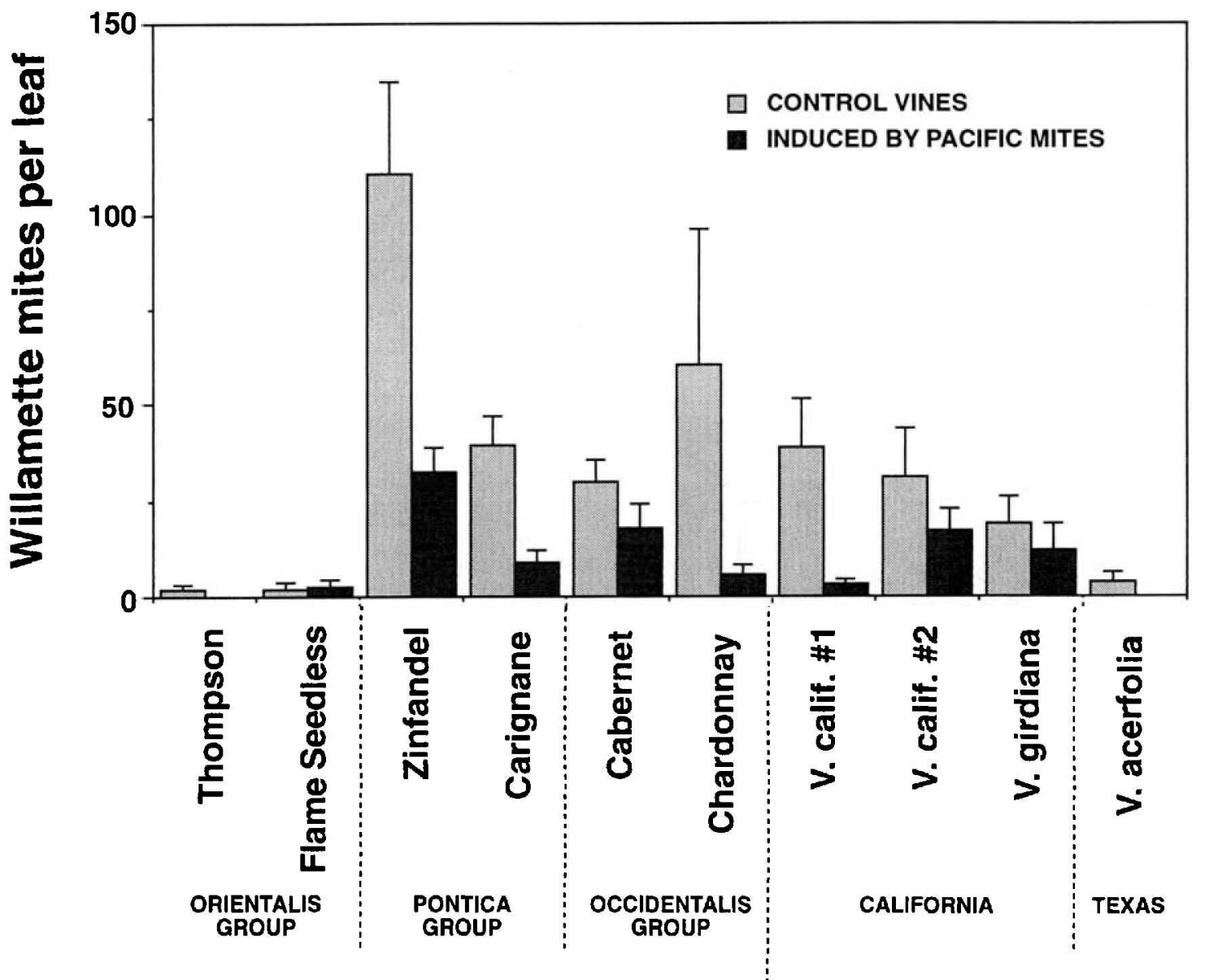

\section{OLD WORLD}

NORTH AMERICAN

Fig. 2. Mean number of Willamette mites per leaf $( \pm 1 \mathrm{SE}$ ) during midseason on 10 different grape cultivars or species for vines that were not damaged early in the season by mites (hatched bars represent a measure of constitutive resistance) or damaged early in the season by Pacific mites (dark bars represent a measure of induction). See text for a description of the 3 different groups of Old World V. vinifera cultivars and taxonomic relatedness of the three species of North American Vitis.

level of induction present in Thompson Seedless, Flame Seedless, and V. acerifolia grapes because Willamette mite populations were very low on control plants as well as damaged plants. There was not a strong relationship between population densities of Willamette mites on vines (measure of susceptibility) and the level of induced resistance $(r=0.31, P>0.25$, $n=7$, excluding the table grapes and V. acerifolia).

The bioassay using Pacific mites also showed variation among grape genotypes in constitutive resistance $(P<0.0001$, Table 2$)$. We did not detect any evidence of induced resistance from early-season feeding damage, however $(P=0.90$, Table 2$)$, nor an interaction between grape genotype and early feeding $(P=0.96$, Table 2$)$, nor an effect of block $(P=0.5)$. Population size of Pacific mites was generally highest on Zinfandel and Chardonnay grapes and lowest on all of the North American grape species, especially the Texas species V. acerifolia (Fig. 3). We found intermediate population levels on Carignane, Cabernet
Sauvignon, Thompson Seedless, and Flame Seedless grapes. These results suggest that constitutive resistance to Pacific mites, although variable, appears to correspond to grape phylogeny with North American species displaying high resistance and $V$. vinifera varieties tending to be susceptible.

Tuble 2. ANOYA resulta assessing effect of vine cultivar or spesies ( 10 types) and type of early-season dumnge (induction with Willamette miles, Pacific mites, or nothing) on Pacific mite populations later in the season

\begin{tabular}{lrcrr}
\hline \multicolumn{1}{c}{ Source } & df & Mean square & \multicolumn{1}{c}{$F$} & $P$ \\
\hline Early damage & 2 & 0.0293 & 0.10 & 0.9047 \\
Vine type & 9 & 4.9470 & 16.95 & 0.0001 \\
Block & 1 & 0.1179 & 0.40 & 0.5258 \\
Damage*Vine & 18 & 0.1443 & 0.49 & 0.9602 \\
Error & 335 & 0.2923 & & \\
\hline
\end{tabular}




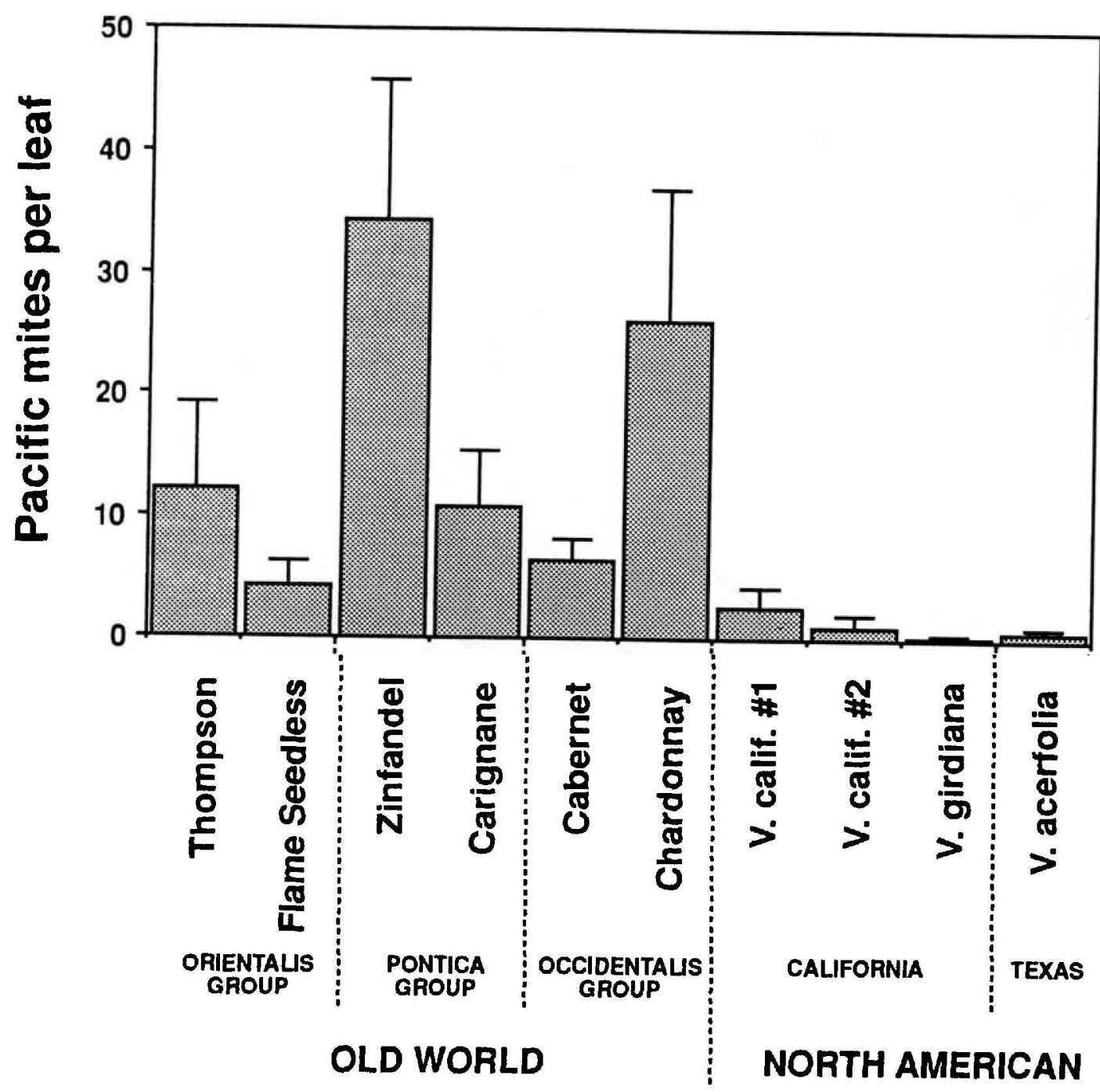

Fig. 3. Mean number of Pacific mites per leaf $( \pm 1 \mathrm{SE}$ ) during midseason on 10 different grape cultivars or species for vines that were not damaged early in the season by mites (a measure of constitutive resistance). See text for a description of the 3 different groups of Old World $V$. vinifera cultivars and taxonomic relatedness of the 3 species of North American Vitis.

\section{Discussion}

We used density of spider mites as our measure of resistance or susceptibility in this study. Based on this measure, we found evidence of variation in constitutive resistance in Vitis for both Willamette mites and Pacific mites. We currently do not have a clear understanding, however, of what factors contribute to this variation or whether the mechanisms of resistance are the same among different varieties or species. The wine varieties Zinfandel and Chardonnay appeared to be particularly susceptible to both Willamette mites and Pacific mites. The mites used to challenge vines in our study were collected originally from Zinfandel grapes and came from areas where both Zinfandel and Chardonnay are the most commonly grown varieties. Thus, origin of challenge mites may be a contributing factor for why they did so well on these varieties. This would not be surprising because some spider mites readily form host plant races (Gould 1978, Brandenburg and Kennedy 1987, Fry 1989, Gotoh et al. 1993).

In terms of constitutive resistance, population densities of Willamette mites and Pacific mites differed most dramatically on the table grape varieties and the North American species. Willamette mites performed poorly on table grapes, but moderately well on North American species (with the exception of the Texas species), whereas Pacific mites performed much better on all $V$. vinifera varieties and poorly on all 3 North American species. Hence, for Pacific mites, grape phylogeny did help explain some of the variation in constitutive resistance. It should be noted, however, that phylogeny and the process of domestication are con- 
founded in this comparison. In other words, Pacific mites may have performed better on $V$. vinifera cultivars compared with North American species because of a shared common ancestor (phylogeny) or because of selection for increased suitability for humans. We currently do not have sufficient information to distinguish between these two alternative hypotheses. The contribution of phylogeny in explaining variation in constitutive resistance to Willamette mites was less apparent. It should be pointed out, as well, that our ANOVA estimates of the relationship between phylogeny and resistance assumes that the mite densities associated with related vine types are independent, an assumption that is likely to be incorrect (Felsenstein 1985).

We were best able to evaluate evidence of genetic variation in induced resistance for vines receiving earlyseason injury from Pacific mites and challenged with Willamette mites. Induced resistance was widespread, occurring both in wine varieties of $V$. vinifera (especially Zinfandel, Carignane, and Chardonnay) and North American species (Fig. 3). It is tempting to hypothesize that induced resistance is an ancestral trait in Vitis, although it is also possible that induced resistance evolved independently in these different lines. Because we do not know the mechanism of induced resistance in grapes, we are not in a position to distinguish between these 2 explanations. Grape phylogeny does not appear to help explain patterns of induced resistance, however. For example, we found strong evidence of induced resistance in $V$. califormica but not in the closely related species V. girdiana. Similarly, although we found strong induction in Chardonnay grapes, we did not in its sister variety Cabernet Sauvignon. Nevertheless, it is clear that induced resistance is not restricted to the cultivated wine variety Zinfandel but occurs in a native species as well.

It has been argued that constitutive resistance and induced resistance should be negatively correlated traits (Mattson et al. 1988, Herms and Mattson 1992). The reasoning behind this hypothesis is that species with high levels of constitutive resistance will derive little benefit from also possessing inducible defenses. We found no evidence of a significant relationship between strength of induction and constitutive resistance. The trend for our data, however, was in that direction: more susceptible species tended to show the strongest induction.

One of the objectives in this study was to assess whether the species identity of the inducer and challenger influenced the outcome of the interaction. We can only partially evaluate this objective. We found that early-season injury by Pacific mites did result in strong induction against Willamette mites whereas early-season injury by Willamette mites did not result in induction against Willamette mites. When the challenging species was Pacific mite, however, we found no evidence of induction by early-feeding injury by either Willamette or Pacific mites. Because of our difficulties in establishing our Pacific mite challenge, we are uncertain how to interpret these results. Certainly, in our previous research, we have shown that early-season feeding by Willamette mites can cause strong induction against Pacific mites for Zinfandel grapes (Hougen-Eitzman and Karban 1995). We do not know why we did not find this result in this study, but one possibility is that our use of a synthetic pyrethroid may have compromised the ability of the plant to be induced. Other experiments will be necessary to evaluate this hypothesis, although some insecticides, including synthetic pyrethroids, have been shown to alter host plant physiology and resistance/ susceptibility against spider mites (Hall 1979, Jones et al. 1986, Brandenburg and Kennedy 1987).

In conclusion, we found evidence that there is a considerable amount of genetic variation for constitutive resistance in Vitis against spider mites. We also found that plant resistance traits are dynamic and will vary depending on previous injury (induced resistance), although the species of herbivore causing the injury and the species subsequently feeding on the plant may influence the outcome. Variation in resistance, for the most part, was not closely linked to grape phylogeny, although the number of species used in our study was relatively small thereby limiting the power of our test. Alternatively, we speculate for species such as spider mites that show rapid population growth, many generations per year, and relatively limited dispersal, that local conditions and local availability of host plants may better predict patterns of resistance and susceptibility than phylogenetic history.

\section{Acknowledgments}

We thank Ed Hall and other technical staff in the Department of Viticulture, University of California Davis, for providing $V$. vinifera cane cuttings and assistance in establishing and maintaining our common garden plot. The staff at the Consumnes River Preserve of the Nature Conservancy kindly allowed us to collect grapes on their property. We gratefully acknowledge the National Germplasm Repository at Winters and $\mathrm{K}$. Rigert for assistance in obtaining cane cutting of native American grapes. Kathy Workman helped us in the field and laboratory and Karen English-Loeb helped with preparing graphics for which we are grateful. We thank Phil Ward and Jennifer Thaler for insights into assessing the role of phylogeny. J. Thaler and 2 anonymous reviewers read the manuscript and offered many useful comments.

\section{References Cited}

Anderson, S. S., K. D. McCrea, W. G. Abrahamson, and L. M. Hartzel, 1989. Host genotype choice by the gallmaker Eurosta solidaginis (Diptera: Tephritidae). Ecology 70: 1048-1054.

Bailey, L. H. 1934. The species of grapes peculiar to North America. Gentes Herb. 3: 149-244.

Bowers, M. D., and N. E. Stamp. 1993. Effects of plant age, genotype, and herbivory on Plantago performance and chemistry. Ecology 74: 1778-1791.

Brandenburg, R. L., and G. G. Kennedy, 1987. Ecological and agricultural considerations in the management of twospotted spider mite (Tetranychus urticae Koch). Agric. Zool. Rev. 2: 195-236.

Brody, A. K., and R. Karban. 1992. Lack of a tradeoff between constitutive and induced defenses among varieties of cotton. Oikos 65: 301-306. 
Campbell, R., and R. M. Macdonald. 1989. Microbial inoculation of crop plants. Soc. Gen. Microbiol. Spec. Publ. 25.

English-Loeb, G. M., and R. Karban. 1988. Negative interactions between Willamette mites and Pacific mites: possible management strategies for grapes. Entomol. Exp. Appl. 48: 269-274.

English-Loeb, G. M., R. Karban, and D. Hougen-Eitzman. 1993. Relative importance of direct and indirect competition in mediating negative interactions between the Willamette mite and the Pacific spider mite feeding on grapes. Ecol. Appl. 3: 699-707.

Felsenstein, J. 1985. Phylogenies and the comparative method. Am. Nat. 125: 1-15.

Fry, J. D. 1989. Evolutionary adaptation to host plants in a laboratory population of the phytophagous mite Tetranychus urticae Koch. Oecologia (Berl.) 81: 559-565.

Gotoh, T., J. Bruin, M. W. Sabelis, and S.B.J. Menken. 1993. Host race formation in Tetranychus urticae: genetic differentiation, host plant preference and mate choice in a tomato and a cucumber strain. Entomol. Exp. Appl, 68: 171-178.

Gould, F. 1978. Resistance of cucumber varieties to Tetranychus urticae: genetic and environmental determinants. J. Econ. Entomol. 71: 680-683.

Hall, R. R. 1979. Effects of synthetic pyrethroids on major insect and mite pests of apple. J. Econ. Entomol. 72: 441-446.

Herms, D. A., and W. J. Mattson. 1992. The dilemma of plants: to grow or defend. Q. Rev. Bio. 67: 283-335.

Hildmann, T., M. Ebneth, H. Peña-Cortés, J. J. SánchezSerrano, L. Willmitzer, and S. Prat. 1992. General roles of abscisic and jasmonic acids in gene activation as a result of mechanical wounding. Plant Cell 4: 11.57-1170.

Hougen-Eitzman, D., and R. Karban. 1995. Mechanisms of interspecific competition that result in successful control of Pacific mites following inoculations of Willamette mites on grapevines. Oecologia (Berl.) 103: 157-161.

Jeppson, L. R., H. H. Keifer, and E. W. Baker, 1975. Mites injurious to economic plants. University of California Press, Berkeley.

Jones, V. P., N. C. Toscano, M. W. Johnson, S. C. Welter, and R. R. Youngman. 1986. Pesticide effects on plant physiology: integration into a pest management program. Bull. Entomol. Soc. Am. 32: 103-109.

Karban, R., and I. T. Baldwin. 1997. Induced responses to herbivory. University of Chicago Press, Chicago.

Karban, R., and G. M. English-Loeb. 1990. A "vaccination" of Willamette mites (Arachnidae: Tetranychidae) to prevent high populations of Pacific mites on grapevines. J. Econ. Entomol. 83: 2252-2257.
Karban, R., and J. H. Myers. 1989. Induced plant responses to herbivory. Annu. Rev. Ecol. Syst. 20: 331-348.

Karban, R., D. Hougen-Eitzman, and G. English-Loeb. 1994. Predator-mediated apparent competition between two herbivores that feed on grapevines. Oecologia (Berl.) 97: 508-511.

Karban, R., G. English-Loeb, and D. Hougen-Eitzman. 1997. Mite vaccinations for sustainable management of spider mites in vineyards. Ecol. Appl. 7: 183-193.

Mattson, W. J., R. K. Lawrence, R. A. Haack, D. A. Herms, and P. J. Charles. 1988. Defensive strategies of woody plants against different insect-feeding guilds in relation to plant ecological strategies and intimacy of association with Insects. Springer, Berlin.

McGregor, E. A. 1950. Mites of the family tetranychidae. Am. Midl. Nat. 44: 257-420.

Miles, D. B., and A. E. Dunham. 1993. Historical perspectives in ecology and evolutionary biology: the use of phylogenetic comparative analyses. Annu. Rev. Ecol. Syst. 24: 587-619.

Moore, M.O. 1991. Classification and systematics of eastern North American Vitis L. (Vitaceae) north of Mexico. Sida 14: 345-348.

Negrul, A. M. 1938. Evolution of cultivated forms of grapes. C.R. Acad. Sci. U.S.S.R. 18: 585-588.

Pritchard, A. E., and E. W. Baker. 1952. A revision of the spider mite family tetranychidae. Memoirs series, vol. 2. Pacific Coast Entomoloigcal Society, San Francisco, CA.

Rhoades, D. F. 1985. Offensive-defensive interactions between herbivores and plants: their relevance in herbivore population dynamics and ecological theory. Am. Nat. 125: 205-238.

SAS Institute. 1990. SAS user's guide, version 6, $4 \mathrm{ed}$. SAS Institute, Cary, NC.

Thaler, J. S., and R. Karban. 1997. A phylogenetic reconstruction of constitutive and induced resistance in Gossypium. Am. Nat. 149: 1139-1146.

White, R. F., and J. F. Antoniw. 1989. The use of plant viruses as inoculants, pp. 79 -87. In R. Campbell and R. M. Macdonald [eds.]. Microbial inoculation of crop plants. Soc. Gen. Microbiol. Spec. Publ. 25.

Zangerl, A. R., and M. R. Berenbaum. 1990. Furanocoumarin induction in wild parsnip: genetics and populational variation. Ecology 71: 1933-1940.

Received for publication 14 March 1997; accepted 20 October 1997. 